\title{
Holding on to happiness
}

\section{Sonja Lyubomirsky welcomes a call for society to encourage people to 'flourish'.}

$\mathrm{T}$ The premise of positive psychology that it is as important to investigate wellness as it is to study misery - has reached the mainstream. Discussed routinely by politicians, educators and mental-health professionals, the field's influence has grown rapidly. Martin Seligman, director of the Positive Psychology Center at the University of Pennsylvania in Philadelphia, is the scholar, educator and charismatic leader who has championed these ideas passionately for more than a decade. In Flourish, his most personal and boldest book so far he argues that we should set aside "happiness" as a goal, and embrace a broader measure of well-being, which he calls "flourishing".

Seligman shares a wealth of insights and stories, mostly compelling and sometimes maddeningly digressing, which cast light on his passions and pet peeves. His wisdom and audacious opinions explain why he has attracted legions of both followers and high-profile critics, including writer and columnist Barbara Ehrenreich and New Yorker journalist Jane Mayer.

Two themes run through the book. The first is that the study of optimal human functioning must be grounded in rigorous science. The second is more controversial: positive-psychology researchers have a duty to make the world a better place. Seligman's book is a paean to applied science, a blueprint for how to translate empirical evidence from the laboratory to the real world.

Seligman describes several applied initiatives that he has conceived and shepherded. In education, he has created and implemented curricula to develop character strengths (such as kindness and leadership), build grit (passion and perseverance) and enhance positive emotions (happiness and gratitude) in schoolchildren and undergraduates. For example, children at risk of depression are guided to identify their top signature strength (such as loyalty) and use it in a new way at school each week. Seligman also teaches the theory and research behind positive psychology to individuals in a range of occupations - from life coaches and entrepreneurs to policy wonks and fitness instructors.

The most impressive effort Seligman discusses is the Comprehensive Soldier Fitness programme now being implemented across the US Army community. The programme, profiled in a special issue of American Psychologist this January, involves measuring "psychosocial fitness" and building resilience in several life domains: emotional, social, family and spiritual. For example, sergeants are trained to avoid thinking the worst when faced with adversities, and soldiers are taught to identify emotions in others. This is a rare

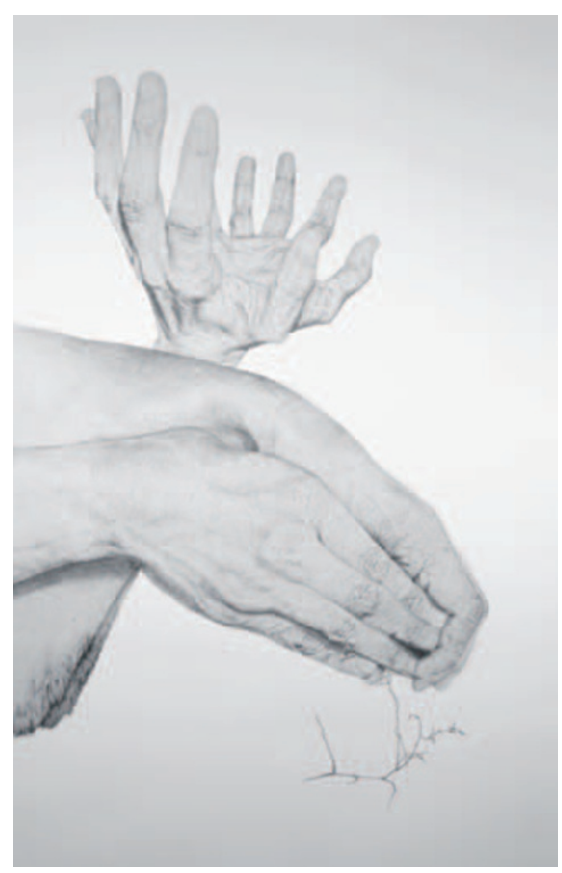

Size Matters: Alces alces (moose email) by Dana Harel, 2009. opportunity to change the culture of a huge institution that is not known for prioritizing emotions, to prevent suffering (including suicide and posttraumatic stress) and bolster both flourishing and effectiveness in military roles.

It is no accident that this book is titled Flourish yet Seligman's preceding best-seller was called Authentic Happiness. He professes that he now

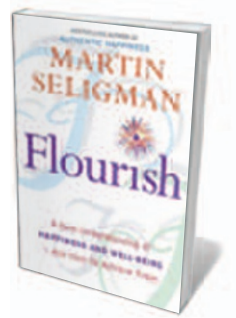

Flourish: A

Visionary New Understanding of Happiness and Well-Being MARTIN SELIGMAN Free Press/Nicholas Brealey Publishing: 2011. $368 \mathrm{pp} / 408 \mathrm{pp}$. $\$ 26 / £ 14.99$ detests the word "happiness", for three reasons: it is overused and nearly meaningless; it is measured subjectively; and it connotes smiley-faced cheerfulness and hedonism. However, the alternative terms proffered by Seligman - flourishing, well-being, meaning, love and growth - are no more likely to elude these problems.

Setting out a new theory of well-being, Seligman posits that flourishing has four elements or pillars: positive emotion (happiness, satisfaction, engagement); meaning positive relationships; and accomplishment (mastery). It is hard to argue with this intuitively appealing thesis. However, it has its weaknesses. First, Seligman's theory confuses the elements of well-being with the contributors and consequences of wellbeing. For instance, people who report that they are happy are more likely than their less-satisfied peers to have meaning, good relationships and accomplishment in their lives. These factors may be sources of happiness - having a good marriage makes one more happy, for example. Or they may be outcomes - happier people are likely to forge satisfying relationships.

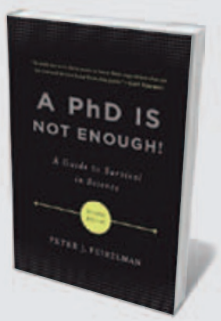

A PhD is Not Enough! A Guide to Survival in Science Peter J. Feibelman (Basic Books, 2011; \$14.95) Climbing the scientific career ladder is difficult, and the first steps from doctoral student to postdoc are the most precarious. Drawing on his experience as a physicist in academic and government labs, in his new edition Peter Feibelman offers career guidance to those entering the research job market.

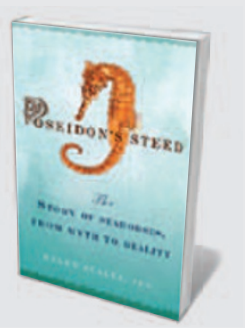

Poseidon's Steed: The Story of Seahorses, from Myth to Reality Helen Scales (Gotham Books, 2010; \$15) The weird world of the seahorse is explored by marine biologist Helen Scales. She describes its peculiar biology and the threats it faces, and reveals its importance to humans, from its role in Chinese medicine to ancient seahorse myths. 
